\title{
Transient Symptomatic Bilateral Optic Disc Oedema Following Lumbar Spinal Surgery- An Unusual Presentation
}

\author{
Vijaya Jojo, Surendra Prasad Jakhanwal \\ Tata Main Hospital, Jamshedpur, India \\ Email:vijayajojo@gmail.com,Spjmeeta07@gmail.com
}

How to cite this paper: Jojo, V. and Jakhanwal, S.P. (2017) Transient Symptomatic Bilateral Optic Disc Oedema Following Lumbar Spinal Surgery-An Unusual Presentation. Open Journal of Ophthalmology, 7, 124-128.

https://doi.org/10.4236/ojoph.2017.72017

Received: April 20, 2017

Accepted: May 21, 2017

Published: May 24, 2017

Copyright $\odot 2017$ by authors and Scientific Research Publishing Inc. This work is licensed under the Creative Commons Attribution International License (CC BY 4.0).

http://creativecommons.org/licenses/by/4.0/

\begin{abstract}
Background: Optic disc oedema has various underlying pathologies, however, unless visually disabling does not usually bring a patient to the physician. The more common symptoms of headache, nausea and vomiting lead to the incidental detection of bilateral disc oedema [1]. Optic disc oedema seen following spinal surgery is usually associated with visual acuity changes and often goes by the acronym POVL (Peri/ postoperative visual loss) wherein, as the name goes, visual acuity changes are profound [2] [3] [4]. Purpose: We would like to highlight a case of transient Bilateral Optic Disc oedema following Lumbar spinal surgery maintaining normal visual acuity and attaining spontaneous resolution. Case Report: A 42-year-old female presented with transient obscuration of vision and flashes of light post an uneventful lumbar spinal surgery. Ophthalmic evaluation revealed normal visual acuity and pupils but marked disc edema right more significant than left. There was no colour vision deficit, neither any field changes. By a process of exclusion, it was likely the patient had developed bilateral disc oedema secondary to the spinal surgery. On follow-up 6 weeks and 3 months later, the oedema had completely settled and visual acuity remained at 6/6. Conclusion: Optic disc oedema can be unilateral or bilateral with some of the uncommon conditions mentioned secondary to spinal surgery, however, in those situations, visual loss has been severe and permanent. Our case is unusual in its combination of disc edema with normal acuity along with its transient nature and resolution and to our knowledge, has not been published before.
\end{abstract}

\section{Keywords}

Transient, Optic Disc Oedema, Lumbar Spinal Surgery, Normal Visual Acuity

\section{Introduction and Literature Review}

Bilateral disc oedema is seen more commonly due to raised intracranial pressure 
inflammatory, vascular, compressive, infiltrative toxic, hereditary and rarely hypotony [5]. The presence of bilateral disc oedema post non ocular surgery is not a very common condition but has been documented. Ischemic optic neuropathy, central retinal artery occlusion (CRAO) and cortical blindness have been noted as the possible final diagnoses [3]. The various risk factors identified are pre-existing diabetes, anaemia, age over 50, small cup disc ratio, intraoperative hypotension and prolonged operative time in the prone position [6]. However, in these visual acuity loss seemed to be the predominant feature apart from field changes, our patient was unique in the absence of any visual loss as such and it was more interesting to note the spontaneous resolution of the same without any treatment leaving behind no significant sequelae.

\section{Case Report}

A 42-year-old healthy female patient reported for a routine outpatient clinic appointment with complaints of "black spots of in front of her eyes along with flashes and transient obscuration of vision". She was unsure as to which eye it exactly emanated from but insisted it had been happening only since her spinal surgery for a lumbar discogenic prolapse a month prior. She was certain that she had no headaches or blurred vision. She had no prior history of similar symptoms apart from her usual refractive correction. She was a well-controlled diabetic for the past 2 years and was on oral hypoglycaemic agents for the same.

Her examination findings showed a BCVA 20/20 both eyes and normal reacting pupils. Her colour vision was normal on Ishihara testing and dilated fundus examination showed the presence of bilaterally hyperemic elevated optic discs with splinter haemorrhages and tortuosity of vessels. Presence of mylinated nerve fibres on the left eye was also noted. The vitreous was clear and the fundus did not show any other signs suggestive of an underlying inflammatory condition. An urgent neurosurgical opinion was sought to ensure absence of any intracranial pathology attributing to her condition. She was formally evaluated by the neurosurgeon and MRI was performed which however came up negative for any abnormality. The patient was otherwise asymptomatic and in view of recent spinal surgery was hesitant to undergo any other invasive testing such as a Lumbar puncture which thereby was deferred. She also had a complete haematological profile to rule out any inflammatory focus attributing to the condition. Simultaneously a carotid Doppler and cardiology evaluation was done to rule out any other cause for her TIA like symptoms which were reported as normal.

Figures 1-4 (images 1 to 4): Fundus changes at presentation and resolution at 6 weeks.

The patient was followed up at 6 weeks and 3 months and at last visit the oedema had completely settled without any treatment. Currently the patient has been advised close follow up to monitor for any worsening or new changes.

\section{Discussion}

Postoperative visual loss (POVL) following spinal surgery is well documented. 


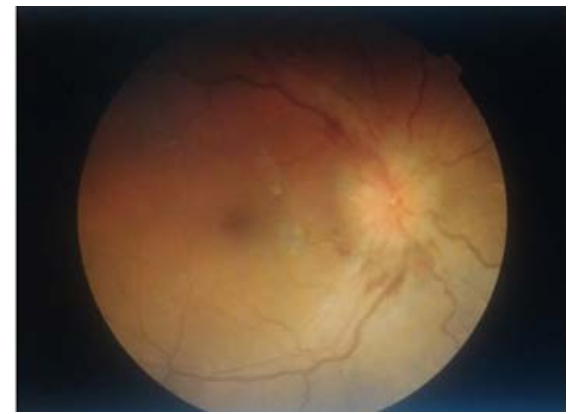

Figure 1. Right eye-blurred disc margins splinter haemorrhages, vascular tortuosity.

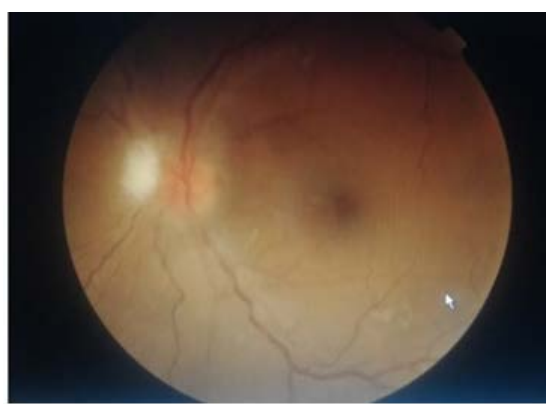

Figure 2. Disc oedema, blurred margins vascular tortuosity mylinated nerve fibres.

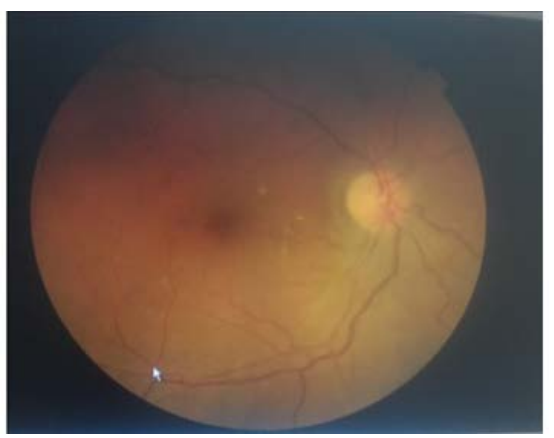

Figure 3. Right eye 6 weeks later mild tortuosity, clear disc margins.

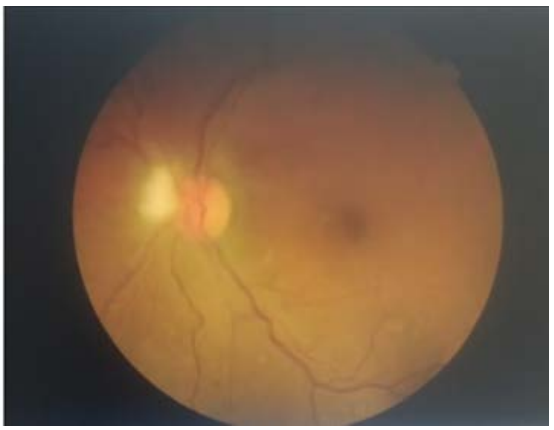

Figure 4. Weeks later-mildtortuosity, no disc oedema, mylinated nerve fibres.

Stevens et al. reported $0.20 \%$ incidence of ischemic optic neuropathy after spinal 
surgery [7]. Nickels et al. have published a detailed analysis of POVL and clearly identified the risk factors and diagnoses where ischemic optic neuropathy seemed to be an important cause for the loss of vision with Anterior ischemic optic neuropathy (AION) being the more common one [3]. Significant blood loss also has been postulated as one of the mechanisms of visual loss [6] [8].

Our patient was notably different in that she did not have any visual loss whatsoever and her insistence that her symptoms started only post-surgery warranted a fundus evaluation The presence of normal acuity, pupils and colour vision pointed out more in favour of a papilledema like picture rather than and ischemic optic neuropathy which has till date been documented as above. Her symptoms of transient obscuration of vision are similar to what Sadun et al. reported in group of patients with transient obscuration of vision with elevated optic disc indistinguishable from those with papilledema [9]. The underlying mechanism postulated there seems to be the transient ischemia with consequent increased pressure and influx of interstitial fluid. There is strong possibility that our patient had a similar underlying pathology to account for her symptoms however it is difficult to ascertain the mechanism of the disc oedema itself. One possibility is that the prone position could have caused some changes in the CSF pressure and indirectly caused her condition however studies by Abel et al. [10] did not find any statistical difference in the CSF pressure and patient positioning. The caveat to our situation is that keeping patient's safety a priority we were unable to do further invasive tests such as a lumbar puncture/cerebrospinal fluid (CSF) opening pressure which may have resolved our dilemma. In fact, due to the recent lumbar spinal surgery our patient was not willing to undergo any further invasive testing.

An alternative diagnosis which could be postulated is a rare occurrence of diabetic papillopathy (DP). There is not enough clarity on the exact mechanism of DP but the risk factors for development has been postulated as small discs, acute control of diabetes and long duration of diabetes and ischemia as the underlying mechanism [11] [12]. DP usually resolves spontaneously as in our case however the patient's profile makes this a doubtful diagnosis. Again one cannot ascertain how spinal surgery could have triggered the same, which again would be a rarity in itself. Solely on clinical findings and by means of exclusion, we could but safely come to the conclusion that at this point, our patient did not have features suggestive of an ischemic neuropathy neither any intracranial space occupying lesions to account for the clinical picture. The fact that her symptoms and oedema spontaneously settled makes our patient even more unique.

\section{Conclusion}

Ophthalmological complication as mentioned is well documented post spinal surgery. However, to our knowledge, there have been no reports of bilateral optic disc oedema with normal visual acuity post spinal surgery that also settled without any complications. Further investigations could perhaps add to the un- 
derlying mechanism, however, at this point, careful follow-up could be the only way forward without compromising the status of our patient and observe for so similar rare incidents to help postulate the underlying mechanism for the same.

\section{References}

[1] Whitening, A. and Johnson, L.N. (1992) Papilledema: Clinical Clues and Differential Diagnosis. American Family Physician, 45, 1125-1134.

[2] Kamming, D. and Clarke, S. (2005) Postoperative Visual Loss Following Prone Spinal Surgery. British Journal of Anaesthesia, 95, 257-260. https://doi.org/10.1093/bja/aei173

[3] Nickels, T.J., Manlapaz, M.R. and Farag, E. (2014) Perioperative Visual Loss after Spine Surgery. World Journal of Orthopedics, 5, 100-106. https://doi.org/10.5312/wjo.v5.i2.100

[4] Li, A., Swinney, C., Veeravagu, A., Bhatti, I. and Ratliff, J. (2015) Postoperative Visual Loss Following Lumbar Spine Surgery: A Review of Risk Factors by Diagnosis. World Neurosurgery, 84, 2010-2021. https://doi.org/10.1016/j.wneu.2015.08.030

[5] Miller, N.R., Newman, N.J., et al., Eds. (2008) Walsh \& Hoyt's Clinical NeuroOphthalmology: The Essentials. $2^{\text {nd }}$ Edition, Lippincott Williams \& Wilkins, Philadelphia, 122-145.

[6] Stang-Veldhouse, K.N., Yeu, E., Rotherberg, D.M. and Mizen, T.R. (2010) Unusual Presentation of Perioperative Ischemic Optic Neuropathy Following Major Spine Surgery. Journal of Clinical Anesthesia, 22, 52-55. https://doi.org/10.1016/j.jclinane.2009.01.018

[7] Steven, W.R., Glazer, P.A., Kelley, S.D., Lietman, T.M. and Bradford, D.S. (1997) Ophthalmic Complications after Spinal Surgery. Spine, 22, 1319-1324. https://doi.org/10.1097/00007632-199706150-00008

[8] Newman, N.J. (2008) Perioperative Visual Loss after Non Ocular surgeries. American Journal of Ophthalmology, 145, 604-610. https://doi.org/10.1016/j.ajo.2007.09.016

[9] Sadun, A.A., Currie, J.N. and Lessell, S. (1984) Transient Obscuration with Elevated Optic Discs. Annals of Neurology, 16, 489-494. https://doi.org/10.1002/ana.410160410

[10] Abel, A.S., Brace, J.R., Mckinney, A.M., Friedman, D.I., Smith, S.D., et al. (2014) Effect of Patient Positioning on Cerebrospinal Fluid Opening Pressure. Journal of Neuro-Ophthalmology, 34, 218-222. https://doi.org/10.1097/WNO.0000000000000074

[11] Giuliari, G.P., Sadaka, A., Chang, P.Y. and Cortez, R.T. (2011) Diabetic Papillopathy: Current and New Treatment Options. Current Diabetes Reviews, 7, 171-175. https://doi.org/10.2174/157339911795843122

[12] Slagle, W.S., Musick, A.N. and Eckermann, D.R. (2009) Diabetic Papillopathy and Its Relation to Optic Nerve Ischemia. Optometry and Vision Science, 86, e395-e403. https://doi.org/10.1097/opx.0b013e318198927c 
Submit or recommend next manuscript to SCIRP and we will provide best service for you:

Accepting pre-submission inquiries through Email, Facebook, LinkedIn, Twitter, etc. A wide selection of journals (inclusive of 9 subjects, more than 200 journals)

Providing 24-hour high-quality service

User-friendly online submission system

Fair and swift peer-review system

Efficient typesetting and proofreading procedure

Display of the result of downloads and visits, as well as the number of cited articles Maximum dissemination of your research work

Submit your manuscript at: http://papersubmission.scirp.org/

Or contact ojoph@scirp.org 